
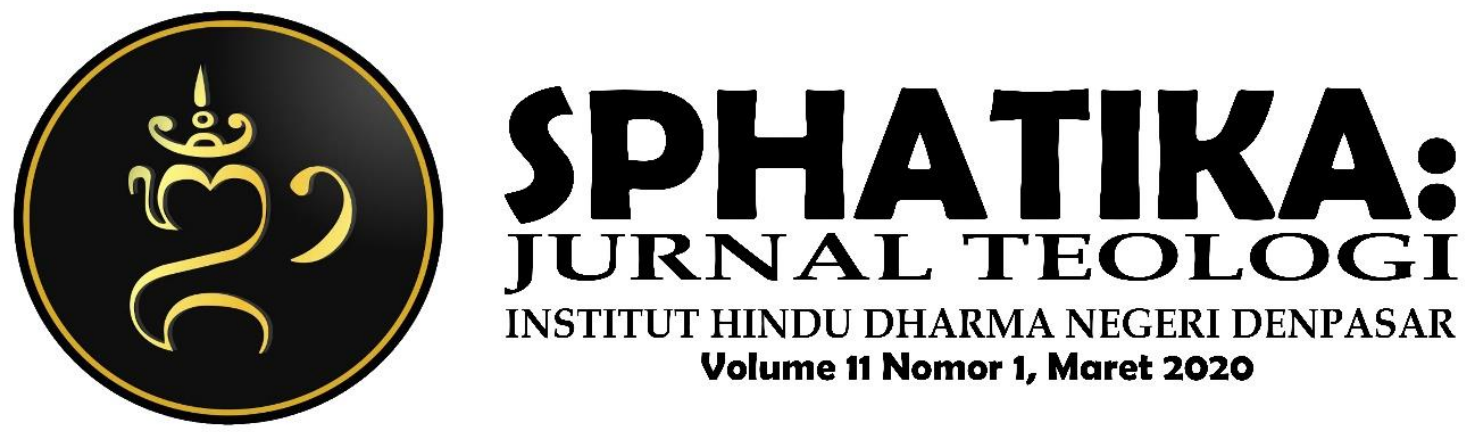

INSTITUT HINDU DHARMA NEGERI DENPASAR

Volume 11 Nomor 1, Maret 2020

\title{
SANG PARAJNYAN DAN SANG PRETANJANA DALAM TUTUR JATISWARA
}

\author{
Yunitha Asri Diantary Ni Made \\ Ayu Veronika Somawati
}

STAH Negeri Mpu Kuturan Singaraja

\begin{tabular}{|ll|}
\hline Keywords: & ABSTRACT \\
\cline { 2 - 2 } Pretanjana, Tutur Jatiswara & Humans are God's creations given the ability more \\
than other creatures, humans also live always side by side \\
with good and bad. Therefore humans in living their lives \\
need an awareness of the importance of applying religious \\
teachings in order to minimize all things that are bad, \\
because it will be futile to be born a human being if it does \\
not improve. Very difficult as a human being and very \\
short, so humans must use their lives with good karma for \\
the creation of a peaceful and prosperous life. In his \\
speech, Jatiswara explained that a father gives advice or \\
advice to his children to always be obedient and act well \\
according to the instructions explicitly and implicit in \\
religious literature, also explained about the good man \\
whoalways prioritizes the dharma in carrying out his life \\
(the Parajnyan) and humans with poor qualities that make \\
adharma as a guide to live their lives (the Pretanjana). \\
This speech explains the various concepts of religious \\
teachings that are very important, one of them is the \\
teachings of karma phala, dharma and religion. Also \\
explained in Tutur Jatiswara about the impact of dharma \\
teachings that do not distinguish humans from social and \\
economic aspects. The method used in this study is a \\
descriptive method that will systematically describe the \\
concepts of good (dharma) and bad (adharma) or the \\
Parajnyan and the Pretanjana in Tutur Jatiswara
\end{tabular}




\section{PENDAHULUAN}

Kemilau kehidupan yang mewah, gaya hidup yang cendrung hedonis membuat manusia lupa akan ajaran dan nilai-nilai agama yang diyakininya. Semakin jauhnya manusia dari ajaran-ajaran agama memang tidak memungkiri bahwa manusia lahir dari sebuah dosa dan dibelenggu oleh awidya. Namun di satu sisi manusia memiliki sebuah keistimewaan, sejatinya lahir menjadi manusia dapat hal yang utama karena dapat memperbaiki diri dari perbuatan adharma, sehingga dapat melenyapkan karma buruk di kehidupan sebelumnya. Perbuatan baik-buruk, suka-duka, semuanya akan berakibat pada segala macam pemikiran, perkataan, dan perbuatan baik maupun buruk yang diwadahi oleh ruang dan waktu.

Menurut Suraba (2013:163) Dalam kitab Bhagavadgitapun dijelaskan mengenai suka dan duka, panas maupun dingin, untung rugi, pujian dan kritik, harus dihadapi dengan pikiran yang tenang dan seimbang. Ketenangan pikiran, ketegaran hati merupakan sumber ketegaran jiwa. Hal ini tentu hanya di dapat dengan latihan spiritual untuk menyadari betapa pentingnya ta pa, brata, yoga dan semadi. Karena ajaran pengendalian diri, ajaran keindahan, ajaran kesucian, ajaran kebenaran sangat sarat terdapat di dalamnya. Oleh karena itu, pemaknaan akan nilai kehidupan tersebut sesungguhnya dapat didalami, salah satunya dengan mempelajari berbagai jenis lontar yang ada. Tutur Jatiswara merupakan salah satu lontar dengan karakteristik tutur. Lontar ini memuat berbagai macam ajaran agama yang dapat diterapkan dalam kehidupan manusia, guna menjadi manusia yang mengunggulkan dharma.

\section{PEMBAHASAN}

\section{Intisari Ajaran Tutur Jatiswara}

Tutur Jatiswara ini banyak menguraikan ajaran dharma yang termuat dalam kitab suci. Teks ini menjelaskan mengenai eksistensi Sang Hyang Jiwa (Atman) yang memiliki peran memberikan kehidupan bagi manusia. Petuah ini memberi motivasi manusia jika mengikuti dan mengimplementasikan ajaran sastra ini dalam kehidupan sehar-hari, sehingga terjadi transformasi atau perubahan diri menuju kehidupan yang lebih baik, lebih berdaya guna dan efektif dalam rangka mencapai 
tujuan Agama Hindu, yakni Moksa (kebahagiaan sepiritual, bersatunya Sang Diri/Ātmà dengan Sang Hyang Widhi, Tuhan Yang Maha Esa) dan Jagadhita yang kemakmuran jasmani dalam kehidupan di dunia ini. Transformasi diri menuju ke arah yang lebih baik disebut sebagai usaha para Manava (umat manusia) menuju Manava-Madhava atau Manava-Devatà (manusia yang berbudhi pekerti yang luhur atau manusia sujana, yang hidupnya senantiasa manis, penuh keramahan, mendapat pencerahan ketuhanan) dan sebaliknya tidak jatuh menjadi ManavaDanava atau Manava-Rakûasa (manusia yang diliputi oleh sifat-sifat kebinatangan atau raksasa, rakus, dan jahat).

Laksana Dharma juga menjadi topik petuah yang dilontarkan dalam Tutur Jatiswara, yang mana penjelasnnya mengenai keutamaan dalam melaksanakan dharma. Dijelaskan bahwa tidak ada perbuatan yang lebih utama dari pada berbuat dharma. Bila kita berbuat dharma (dana) terhadap orang miskin dengan mengharapkan imbalan maka kita tidak akan jadi berdharma. Orang Budiman akan selalu kukuh dan teguh dalam melaksanakan dharma karena itu telah tersirat dalam sastra agama, dan yang tidak kalah penting adalah pelaksanaan dharma sadana sebagai wujud kemantapan hati dalam kehidupan beragama. Sebagaimana hal ini dijelaskan dalam Tutur Jatiswara sebagai berikut:

Awanan sang prajnan pageh gati nglaksanayang laksana keto, kadugi patuhan Ida solah Ida ne bhakti nyungsung ragane teken padewekan anake elenan, solahe keto maadan Laksana dharma. Pangubhaktine bahan laksana darma madan: darma sadana Terjemahan: mateges paweweh saking darma.

Sebabnya orang yang pandai sangat teguh melaksanakan perbuatan yang demikian, sehingga disamakan tingkah laku beliau (seperti) hormat dan tunduk pada diri sendiri terhadap orang lain, perbuatan itu dinamakan Laksana Dharma. Sujud bhaktinya berdasarkan perbuatan baik disebut dharma sadana, artinya pemberian dari dharma.

Selain mengenai etika menjalani kehidupan, teks ini juga menjelaskan yang menyebabkan makhluk mati yaitu Sang Hyang Pati (Kalamretyu). Namun dijelaskan pula bahwa yang mati itu adalah raganya, bukan jiwanya. Jiwa ini akan hidup di alam niskala dengan membawa hasil perbuatan yang diperbuat di dunia. Melaksanakan upacara yang besar tidak akan dapat mengubah hasil perbuatan. 
Maka dari itu diarahkan selalu untuk berbuat baik selagi kita hidup. Sebagaimana pula yang dijelaskan dalam teks ini :

Yuadin buka apa baan ngedenang pangupakarane, apang mangdene sida buwung naraka, sinah tusing dadi, upmama: cening malaksana jele (mamaling) tur patut sisip. Yuadin buka apa baan bapa ngaenang cening pangupakara apang sida cening Terjemahan: tusing sisip, sinah tusing nyidayang.

Walaupun sebesar apapun upacara (yang dibuatkan) untuk membatalkan mendapat neraka, tentu tidak akan bisa, umpamanya: kamu berbuat tidak baik (mencuri) pasti disalahkan. Walau sebesar apa ayah membuatkan upacara agar bisa kamu tidak salah, pasti tidak akan mungkin.

Keinginan juga merupakan penyebab manusia dapat berbuat baik maupun buruk, ini sebabnya keinginan yang paling berkuasa jika tidak dikendalikan. Dalam tutur ini keinginan yang menyebabkan orang berbuat tidak baik akan memproleh kesengsaraan lahir batin dinamakan indriya. Dijelaskan pula mengenai 2 jenis manusia yaitu manusia yang selalu berbuat demi kebaikan yang dinamakan: Sang Parajnyan dan manusia yang selalu berbuat menimbulkan kesengsaraan dinamakan :Pretanjana. Kesimpulannya keinginan ini wujud dari sorga dan neraka (baik dan buruk). Jika kita bisa memilih jalan menjadi manusia Sang Parajnyan ini maka akan mencapai kebahagiaan lahir batin.

\section{Sang Parajnyan dan Sang Pretanjana dalam Tutur Jatiswara}

Mengenai Sang Parajnyan dan Pretanjana merupakan dua golongan manusia yang dibedakan berdasarkan sifatnya. Sang Parajnyan yang berarti manusia yang selalu berbuat kebaikan, sedangkan yang selalu berbuat buruk dinamakan Pretanjana. Kedua sifat ini mendapatkan pengaruh kuat dari “keinginan”.

Dalam hal ini, manusia yang memilih hidupnya menjadi manusia dengan kualifikasi Sang Parajnyan akan mengatur pikirannya dengan baik, dengan mengelola pikiran ke arah yang positif maka akan mengantarkan atman dalam diri mencapai moksa. Begitu pula dengan memupuk kejujuran, kelembutan, dan keindahan merupkan sifat dari pikiran satvika yang akan mengantarkan raga manusia memiliki pengetahuan tentang Tuhan sehingga dapat membedakan antara benda dan batas-batasnya. Begitu juga dengan sebaliknya, jika manusia memilih 
untuk mengaplikasikan sifat-sifat yang buruk dalam dirinya, berarti dia memilih menjadi manusia tipe Pretanjana yang memiliki sifat angkuh, kejam, serakah.

Manusia dengan jenis Pretanjana akan mengaplikasikan sifat-sifat buruk di atas di dalam kehidupannya sehari-hari. Sifat rajas yang unggul dalam dirinya, hati bersifat bengis, prilaku penuh amarah dan menakutkan, angkuh, dan suka kekerasan. Ia garang dan serakah. Manusia jenis Pretanjana ini akan tidak menemukan kebahagiaan dalam dirinya, karena ia tidak pernah bersyukur dan selalu ingin memiliki apa yang dimiliki orang lain.

Menurut Suratmini (2012:77) menjelaskan manusia itu memiliki unsur kontrol untuk kendali terhadap hasil proses intlektualnya dan kreativitas agar tidak bergerak kearah egoistis, menghalalkan segala cara untuk mencapai sukses, bergerak kearah orang lain menderita dan susah. Budhi ibarat cermin yang berfungsi untuk memahami dan merasakan apakah hasil proses berpikir kita sudah mengarah kepada kesejahteraan dan kebahagiaan manusia. Budhi merupakan alat kendali untuk menimbang-nimbang proses berpikir dan pola tindakan yang dilakukan di dunia ini. Dengan budhi seseorang menjadi arif dan bijaksana, yang menyebabkan seseorang termotivasi untuk berbuat baik. Manusia hanya dapat merasakan kedamaian dalam hidupnya bila mereka menyertakan budhi dalam proses berpikirnya.

Bila kita senantiasa berpegang kepada ajaran agama dan selalu mendekatkan diri dengan Tuhan Yang Maha Esa, para dewata dan leluhur, nisacaya hidup kita akan tentram dan Bahagia dan menjadi manusia dengan kualitas Sang Parajnyan. Selain itu untuk membedakan manusia dengan klasifikasi Sang Parajnyan dan Sang Pretanjana dalam dilihat dari konsep tri kaya parisdudha. Seorang Prajnyan pasti menjadikan ajaran suci ini sebagai pedoman kehidupannya, begitu pula sebaliknya manusia dengan jenis Pretanjana tidak akan mengindahkan ajaran agama ini di dalam hidupanya, ia akan berjalan dengan keangkuhan dan egonya saja. Pada nyatanya konsep dari ajaran suci Tri Kaya ini sangat penting dalam kehidupan sehari-hari untuk memupuk karma yang baik dan menentukan keberhasilan menjelma sebagai manusia. 
Seorang Parajnyan pasti memiliki ilmu pengetahuan yang menjadi dasar dalam segala tingkah lakunya. Pengetahuan itu sebagai kunci kesejahteraan dan kehidupan yang damai. Dalam pandangan Hindu, ilmu pengetahuan itu dapat dibagi menjadi dua yaitu paravidya yang berarti pengetahuan yang berkaitan dengan ajaran ketuahanan (rohani), melalui pengetahuan ini manusia akan belajar akan kehidupan dan mengantarkan kepada kedamaian yang abadi. Sedangkan pengetahuan lainnya disebut dengan aparavidya yang berarti ilmu pengetahuan yang berkaitan dengan kehidupan keduniawian (jasmani), pengetahuan ini jika diterapkan akan mengantarkan manusia kepada kualitas kehidupan yang baik, dan melalui pengetahuan ini dapat dipergunakan dalam mencari kesejahtera an hidup di dunia. Sejalan dengan pentingnya menerapkan kedua pengetahuan ini dalam kehidupan, dalam kitab Slokantara juga menjelaskan betapa bermaknanya pengetahuan tersebut.

Jika dipandang dari segi pengetahuan, hal ini yang membedakan antara Sang Parajnyan dan Pretanjana. Betapa pentingnya ilmu pengetahuan dalam mengantarkan tujuan kehidupan kita. Dalam Tutur Jatiswara dijelaskan pula beberapa perbuatan yang dapat dipakai sebagai pengendali jalannya keinginan, serta bagiannya ada sepuluh yang terdiri dari perbuatan yang bersumber dari pikiran ada tiga (pengendaliannya) bagian, yaitu:

a. tidak merasa iri dengan kepunyaan orang lain

b. tidak menyakiti makhluk hidup

c. percaya dengan adanya karma phala yang merupakan hasil perbuatan baik dan buruk

Dari perkataan ada empat (pengendaliannya) yaitu:

a. berkata yang menyebabkan orang sakit hati

b. menghardik

c. memfitnah

d. berkata berbohong, sombong

Keempat hal tersebut hendaknya jangan diperbuat, apalagi untuk mengucapkan hal itu, jauhkanlah hal itu dari pikiran untuk berkata demikian. Dan dari segi perbuatan: 

a. membunuh; membunuh sesuatu yang tidak sepantasnya dibunuh
b. mecuri; mencuri segala yang tidak patut dicuri
c. berzina (memperkosa), memaksa yang tidak patut dipaksa

Ketiga hal tersebut jangan diperbuat terhadap orang yang tidak disenangi, demikian pula terhadap orang lain, karena (lakukan) perbuatan, perkataan, dan pikiran yang membuat orang senang, sebab perbuatan baik selalu dilaksanakan, (disampingkan) berkata dan berpikir. Segala hal ini bermuara dari keinginan. Keinginan memiliki peranan dalam kehidupan ini, sebagaimana dijelaskan dalam Tutur Jatiswara:

Awanan yan ada nyidayang ngundukang keneh sinah nemu suka di sakala niskala, dening kenehe ngranayang melaksana jele wiadin melah, awanan kenehe buatang ngungkang, buina kenehe tuwuh ngantinin paninghalane maliat apang nyidayang tawang ane liatin, yan tusing makanti bahan keneh, wiadin liatang paninghalane, sinah tusing tawang ane liatin, awanan kenehe madewek rengha adane tur wisesa.

Terjemahan;

Sebabnya bila ada orang yang dapat mengendalikan keinginan (pikiran) pasti menemui kebahagiaan lahir bhatin, karena keinginan yang menyebabkan orang berbuat baik dan buruk, sebabnya keinginan itu diusahakan untuk mengendalikannya, juga keinginan (indriya) yang membuat mat aitu dapat mengenal apa yang dilihat, bila tidak ada keinginan (indriya), walaupun mata memandang sesuatu pasti tidak akan tahu apa yang dilihat, sebabnya keinginan berwujud kesadaran dan berkuasa.

Dari sekian jenis penjelmaan, hanya menjelma menjadi manusialah yang paling baik (utama), karena hanya manusia yang dapat berbuat baik dan buruk serta membedakan dua perbuatan tersebut. Dan hanya manusia saja yang dapat memperbaiki perbuatan yang tidak baik dengan perbuatan yang baik. Meski lahir menjadi manusia dengan berbagai kekurangan dalam kehidupan, namun menjadi menjelma menjadi manusia perlu berbesar hati, karena lebih utama dari penjelmaan makhluk lainnya.

\section{Implikasi Ajaran Dharma dalam Tutur Jatiswara}

Ajaran dharma memiliki peranan yang sentral dalam kehidupan, setiap pelaksanaan dharma yang dilakukan pasti akan membawa dampak tersendiri bagi kehidupan manusia. Dharma ini akan mengantarkan kita pada tahap kehidupan yang bahagia. Sejalan dengan hal ini, dalam Tutur Jatiswara dikatakan bahwa 
perbuatan yang dipakai sebagai sarana mencapai untuk mencapai kebahagiaan (mencapai sorga) karenanya bila ingin mendapat kekayaan dan kesenangan, darmalah yang terlebih dahulu diperbuat, pasti akan menemukan kekayaan dan kesenangan itu, karena tidak baik mendapatkan kekayaan dan kesenangan dengan jalan tidak sesuai dengan kebenaran. Sebagaimana pula dijelaskan dalam Tutur Jatiswara mengenai dampak dari ajaran dharma yang tidak membedakan manusia dari segi sosial dan ekonomi, sebagai berikut.

Tusing gati Ida ngajum anak sugih, dening kabaos tusing jati anake sugih nepukin kalegan, dening kaunggwanan keneh drohaka, dikalane patut madana yadian melegan-legan tan mari keweh gedeg (crewet). Buina kalewihan darmane, tan mari ngranayang rahayun sang ngelaksanayang tur kaanggon kanti bahan sang prajnan. Katerangane tuwah darmane nintingang (ngrahayuang) gumine uli di narakane (darmane ngranayang nyidayang nepukin rahayu suarga)

Terjemahan:

Ia tidak akan memuji orang yang kaya, karena belum tentu orang yang kaya akan mendapatkan kebahagiaan, bila didasari pikiran yang kotor, saat berderma secara sukarela selalu didasari dengan hati benci (cerewet). Lagi pula keutamaan dharma itu, selalu akan membuat orang yang melaksanakannya mendapat Bahagia dan dipakai sebagai teman oleh orang Budiman. Kesimpulannya hanya dharma saja yang mampu mengangkat (membahagiakan) dunia ini dari kesengsaraan (dharma yang dapat menyebabkan kita menemui kebahagiaan sorga)

Ajaran dharma banyak sekali membawa pengaruh positif pada kehidupan manusia, menurut Sivananda (2003:39) dharma merupakan prinsip-prinsip dari kebajikan, kekudusan, dan juga kesatuan. Bhisma berkata dalam perintahperintahnya kepada Yudisthira, bahwa apapun yang menimbulkan pertentangan adalah adharma, dan apapun yang menyudahi pertentangan dan membawa kesatuan dan keselarasan adalah dharma. Apapun yang membantu untuk menyatukan segalanya dan mengembangkan cinta kasih Tuhan dan persaudaraan universal adalah dharma. dharma memberikan akibat kebahagiaan baik di dunia maupun di alam baka. Maharsi Jaimini mendefiniskan dharma sebagai suatu perbuatan yang diperintahkan oleh kitab Weda dan akhirnya tidak menghasilkan penderitaan. Hanya dengan berpihak kepada dharma seseorang akan memperoleh keselamatan, kesejahtraan dan kebahagiaan lahir dan batin. Disebutkan dalam Manavadharmasàstra VIII.15 dinyatakan: Dharma Raksati Dharma Raksitah yang 
artinya mereka yang selalu melaksanakan Dharma, dilindungi oleh Dharma. Adapun terjemahan lengkapnya adalah sebagai berikut.

"Dharma eva hato hanti dharmo rakûati raksitaá, tasmàd dharmo na hantavyo màbo dharmo hato'vadhit.

Terjemahan:

“Dharma yang dilanggar menghancurkan pelanggarnya. Dharma yang dilaksanakan melindungi pelaksananya, oleh karena itu janganlah melanggar Dharma, sebab bagi yang melanggar Dharma akan menghancurkan dirinya sendiri"

Ajaran Dharma juga membawa pengaruh positif akan keharmonisan alam semesta ini. Manusia yang memegang teguh dharma akan membantu menciptakan keharmonisan antar sesame makhluk dan lingkungan tempat tinnggalnya. Ajaran keharmonisan ini dikenal dengan Tri Hita Karana, Istilah Tri Hita Karana berasal dari kata "tri, hita, dan karana". Tri artinya tiga, hita artinya bahagia, dan karana artinya penyebab. Dengan demikian Tri Hita Karana berarti "tiga penyebab kebahagiaan". Nama Tri Hita Karana inilah yang dijadikan untuk menyebutkan ajaran yang mengajarkan agar manusia mengupayakan hubungan harmonis dengan Tuhan, dengan sesame manusia dan dengan alam lingkungannya (Wiana,2007:1). Menurut ajaran Agama Hindu alam dan manusia adalah diciptakan oleh Tuhan berdasarkan yajna. Artinya Tuhan mencipta itu tidak ada kepentingan Tuhan terkait dengan ciptaan-Nya itu. Inilah yang disebut dengan Lila. Mungkin mirip dengan seniman mencipta bukan untuk tujuan komersil atau untuk disanjung-sanjung mencari popularitas. Demikian juga seorang Maha Rsi menjabarkan kitab suci dengan karya sastranya sebagai yajna. Tidak ada tujuan untuk mencari popularitas apalagi komersial. Itulah memang hakekat yajna. Untuk kehidupan alam dan manusia Tuhan menciptakan Rta dan Dharma (Wiana, 2007:21) maka dari itu ajaran dharma tidak pernah lepas dari kehidupan manusia di bumi ini. Melalui ajaran dharma ini manusia mengupayakan keharmonisan tersebut, dari keseimbangan hubungan manusia dengan Tuhannya, manusia dengan sesama manusia dan manusia dengan alam itu akan menimbulkan tiga lingkungan hidup yaitu:
a. Lingkungan Rohani di Parhyangan
b. LIngkungan Sosial di Pawongan
c. Lingkungan Alam di Palemahan 
Penataan Parhyangan untuk memelihara eksistensi lingkungan rohani sebagai media untuk berbakhti pada Tuhan. Penataan pawongan untuk menjaga eksistensi lingkungan sosial agar umat manusia hidup untuk saling mengabdi sesuai dengan swadharmanya masing-masing, sedangkan penataan Palemahan untuk menjaga eksistensi lingkungan alam agar senantiasa menjadi sumber kehidupan dan penghidupan semua makhluk hidup isi alam ini. Tiga lingkungan hidup ini harus dijaga keseimbangan eksisensinya agar terus berlangsung secara kontinyu. Kalau terjadi kepincangan atau kesenjangan diantara ketiga lingkungan itu maka kondisi membangun hidup bahagia atau Hita Purusa tujuan utama Tri Hita Karana menjadi terhalang (Wiana, 2007:23).

\section{SIMPULAN}

Tutur Jatiswara mengandung nasehat seorang ayah (orang tua) yang selalu mengingatkan anaknya agar selalu patuh dan bertingkah yang baik sesuai dengan petunjuk yang tersurat dan terirat di dalam sastra-sastra agama. Orang tua dalam teks ini dianggap sebagai seorang guru sedangkan sang anak adalah murid. Tutur ini banyak menerangkan tentang ajaran agama terutama ajaran dharma dan karma phala yang merupakan hasil dari setiap tingkah laku yang dilakukan dalam kehidupan ini. Dua jenis manusia juga diterangkan dalam teks tersebut, dimana Sang Parajnyan merupakan jenis manusia yang memiliki sifat-sifat baik dan selalu mengamalkan dharma dalam hidupnya sedangkan Sang Pretanjana merupakan kebalikannya, yaitu manusia yang selalu mengutamakan hal-hal buruk dalam menjalankan kehidupannya. Pikiran menjadi kunci dalam menentukan manusia itu hendak menjadi Sang Parajnyan maupun Sang Pretanjana. Pengamalan konsep tri kaya parisuda juga menjadi kunci penting untuk membedakan dua jenis manusia tersebut.

\section{DAFTAR PUSTAKA}

Darmayasa. 1992. Canakya Nitisastra.Jakarta: Hanuman Sakti.

Donder, I Ketut. 2007. Kosmologi Hindu Penciptaan, Pemeliharaan, dan Peleburan Serta Penciptaan Kembali Alam Semesta. Surabaya: Paramita.

Sivananda, Sri Swami.2003. Intisari Ajaran Hindu. Surabaya: Paramita. 
Sudharta, Tjok Rai.tt. Manava Dharmasastra (Manu Dharmasastra). Surabaya: Paramita.

Sudharta, Tjok.2003. Slokantara Untaian Ajaran Etika, Teks, Terjemahan dan Ulasan. Surabaya: Paramita.

Sudharta, Tjok Rai.2009. Sarasamuscaya Smerti Nusantara.Surabaya: Paramita.

Suraba, I Wayan. 2013. Cara Praktis Untuk Memahami Agama Hindu Melalui Kumpulan Dharmawacana. Surabaya: Paramita.

Suratmini, Ni Wayan.2012. Merawat Diri untuk Menjaga Kesucian Lahir Bathin.Surabaya: Paramita.

Tim Penyusun. 2007. Petunjuk Teknis Pelaksanaan Dharma Wacana. Surabaya: Paramita.

Titib, I Made.1996. Veda Sabda Suci Pedoman Praktis Kehidupan. Surabaya: Paramita.

Wardhana, dkk. (1998). Buku Pelajaran Agama Hindu Tingkat SMU Kelas III. Jakarta: Hanuman Sakti.

Wisasmaya, Ida Komang. 2012. Geguritan Sucita Subudi. Surabaya: Paramita.

Zoetmulder, 1995, Kamus Jawa Kuna-Indonesia. 2 Jilid, Terjemahan Darusuprapta, Sumarti Suprayitna, PT. Gramedia Pustaka Utama, Jakarta. 